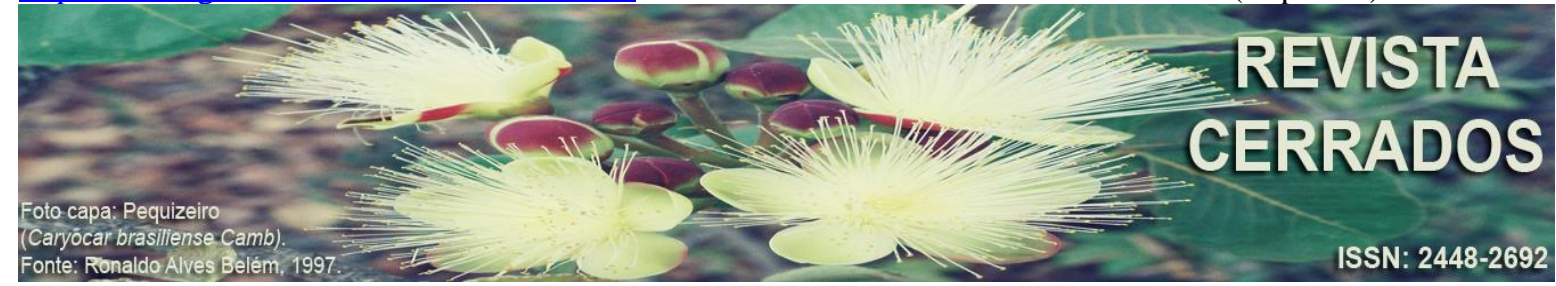

\title{
PRAÇA DAS NAÇÕES E PARQUE ECOLÓGICO CIMBA EM ARAGUAÍNA/TO: espaços públicos na Amazônia legal
}

\section{PRAÇA DAS NAÇÕES AND CIMBA ECOLOGICAL PARK IN ARAGUAÍNA/TO: public spaces in the legal Amazon}

\section{SPÉCIAUX DANS LA VILLE D'ARAGUAINA/TO: Praça das Nações e Parque Ecológico Cimba: Espaces Publics Amazonie légale}

\author{
João de Deus Leite \\ Universidade Federal do Tocantins - UFT, Araguaína, Tocantins, Brasil \\ E-mail: < joaodedeus@mail.uft.edu.br>. \\ Miguel Pacífico Filho \\ Universidade Federal do Tocantins - UFT, Araguaína, Tocantins, Brasil \\ E-mail: <miguilim@mail.uft.edu.br> \\ Izabel Oliveira de Moraes \\ Universidade Federal do Tocantins - UFT, Araguaína, Tocantins, Brasil \\ E-mail: < izabelolimoraes@yahoo.com.br>
}

\begin{abstract}
RESUMO
Particularizamos dois recortes espaciais na cidade de Araguaína/TO: Praça das Nações e Parque Ecológico Cimba, que serão pensados à luz da Análise de Discurso francesa, a partir das teorizações de Orlandi (1999) sobre a "ordem do discurso urbano". Por meio da categoria "organização" produzimos um diálogo com teóricos da geografia e da arquitetura/urbanismo. Definimos aqueles recortes conceitualmente como espaços públicos e problematizamos como são produzidos. Recorremos a um portal de notícias local para enfocar condições de produção, perseguindo o seguinte questionamento: de que modo a ordem do discurso urbano operou efeitos na revitalização daqueles espaços? Percebe-se uma contradição nessa revitalização, já que a "organização" busca inscrever o quê, supostamente, atrapalha a ordem urbana na discursividade da expulsão. Sobre o primeiro espaço, revitaliza-se para ressignificar a infraestrutura precária e expulsar população em situação de rua. Sobre o segundo, revitalizase para ressignificar os "vazios urbanos", impedindo o descarte irregular de lixo. Em ambos, as práticas sociais figuram como subterfúgio para o projeto de urbanização.
\end{abstract}

Palavras-chave: Discurso. Espaço Público. Amazônia. 
LEITE, J. D; PACÍFICO FILHO, M; MORAES, I. O.

Praça das Nações e parque ecológico Cimba em Araguaína/TO: espaços públicos na Amazônia legal

\begin{abstract}
This article discusses the order of urban discourse of two spaces in the city of Araguaina/TO: Praça das Nações and CIMBA Ecological Park. These spaces were defined as public. In order to investigate the way, they were discursively produced a local news portal was used. The guiding question for a such a purpose was to identify how the order of urban discourse produced effects on the revitalization of those spaces. Theoretically, the study is founded on French Discourse Analysis, particularly on Orlandi's reflections (1999) about the order of urban discourse. By using the category of "organization", a relevant dialogue with scholars from the fields of Geography, Architecture and Urbanism became possible. The analysis showed a contradiction since the "organization" seeks to inscribe what, supposedly, disturbs the urban order in the discourse of expulsion. Thus, the implementation of revitalization of Praça das Nações was meant to (re)signify the precarious infrastructure and expel the homeless population present there. To what concerns CIMBA Ecological Park, the process of revitalizing was to provide the "urban voids" with new meanings by preventing irregular disposal of garbage. In both, social practices appear as a subterfuge for the urbanization project.
\end{abstract}

Keywords: Discourse. public places. Amazonia.

\title{
RÉSUMÉ
}

Nous avons distingué deux extraits spéciaux dans la ville d'Araguaina/TO : Praça das Nações e Parque Ecológico Cimba (Place des Nations et Parque Écologique Cimba), qui seront discutés sous la perspective de l'Analyse du Discours française, à partir des théorisations d'Orlandi (1999) sur «l'ordre du discours urbain ». À travers la catégorie « organisation » nous avons produit un dialogue avec des théoriciens de géographie et d'architecture/urbanisme. Nous avons défini ces extraits conceptuellement comme espaces publics et nous avons problématisé leur production. Nous avons fait appel à un portail d'actualités locales pour concentrer les conditions de productions, se posant la question suivante : de quel façon l'ordre du discours urbain a-t-il produit les effets de revitalisation de ces espaces ? On comprend une contradiction dans cette revitalisation, puisque « l'organisation " cherche à inscrire ce qui, soi-disant, dérange l'ordre urbaine dans la discursivité d'expulsion. Sur le premier espace, il se revitalise pour recadrer l'infrastructure précaire et expulser les sans-abris. Sur le deuxième, il se revitalise pour recadrer « les vides urbains » en empêchant l'élimination irrégulier des ordures. Dans les deux cas, les pratiques sociales ne figurent comme subterfuge pour le projet d'urbanisation.

Mots-clés: Discours. Espace Public. Amazonie.

\section{INTRODUÇÃO}

Os estudos sobre os fenômenos urbanos apresentam-se, desde a segunda metade do século XX, como campo de possibilidades distintas de abordagem via perspectivas multidisciplinares. Batista (1969), Rolnik (1988), Carlos (1992, 2011), Maricato (2001, 2015) 
LEITE, J. D; PACÍFICO FILHO, M; MORAES, I. O.

Praça das Nações e parque ecológico Cimba em Araguaína/TO: espaços públicos na Amazônia legal

e Becker $(2010,2013)$ discutem as alterações da percepção e dos usos da cidade por meio de sua historicização; discutem, também, a cidade, como espaço de disputas sociais e de visões de mundo, bem como a delimitação daquilo que se entende como crise urbana. Observamos, também, nessa literatura especializada, perspectivas propositivas para questões estruturantes ao campo de pesquisa e de abordagens regionais, tais como: é possível planejar a cidade? Que vetores, agentes e interesses diversos devem ser mediados nas questões urbanas? Quais as especificidades e as dinâmicas da urbanização na amazônia?

O denominador comum a tal diversidade de olhares, apontado no final da década de 1960, permanece válido para os estudos mencionados anteriormente e reside na compreensão de que a urbanização permite entendimentos e tratamentos diversos, cujos pontos de partida podem encontrar-se na geografia, na sociologia, na arquitetura, no planejamento urbano e no direito, entre tantas outras perspectivas possíveis que discutem o tema (BATISTA, 1969). Uma das características desses olhares são os esforços na busca pela estruturação de análise crítica dos diversos fenômenos que envolvem a urbanização, transformando-a em objeto passível de teorização e análise (LIMONAD, 1999).

Neste artigo, filiamo-nos ao pensamento de que a ocupação e a produção do urbano seguem dinâmicas simbólicas. Para pensar no modo como os espaços públicos de Araguaína/Tocantins são produzidos e/ou revitalizados, enfocamos dois deles: Praça das Nações Dom Orione e Parque Ecológico Cimba Benedito Vicente, localizados na região central da cidade. Ainda que seja a particularização de dois espaços, podemos ressaltar que se torna, cada vez mais, estabilizada a discursividade de que a cidade de Araguaína passa pelo processo de revitalização de seus espaços. Contudo, dado o aporte teórico em que nos embasamos, esse processo é marcado por reestruturação e, também, por contradições. Dadas as especificidades de nosso recorte, a contradição será também uma das vertentes observadas, pois, de acordo com Cabral e Cândido (2019, p. 2): “o urbano tem sido um espaço de crescimento, desenvolvimento e contradições".

Para pensar na perspectiva da revitalização urbana de Araguaína, vamos nos ancorar em teorizações de Moura et al (2006) e de Barreto e Gilson (2013). É comum, nessas teorizações, a concepção de que essa revitalização é fruto de um planejamento estratégico, não perdendo de vista a relação entre os espaços revitalizados, as atividades circunscritas a eles e as pessoas. Na esteira de Moura et al (2006), podemos ressaltar que essa revitalização está em função, por exemplo, da necessidade de se tornar o espaço urbano globalizado, em 
LEITE, J. D; PACÍFICO FILHO, M; MORAES, I. O.

Praça das Nações e parque ecológico Cimba em Araguaína/TO: espaços públicos na Amazônia legal

termos de oportunidade e de vantagens competitivas. Por isso, sob a perspectiva desses autores, há um viés sustentável, marcando o processo de revitalização, já que o intuito é intervir para tornar o espaço revitalizado mais apto e abrangente ao uso e à ocupação. Vejamos, a seguir, as palavras dos referidos autores:

O processo de revitalização desenvolve-se, a médio e longo prazo, numa perspectiva de sustentabilidade da intervenção, articulando as oportunidades, as vantagens competitivas e um urbano cada vez mais globalizado, de expressão localizada. Baseia-se, sobretudo, nos "opportunity projects", na colaboração privado/público (investidores) e na relação com as comunidades. As operações de revitalização tendem ainda a intervir a montante dos factores de desvitalização, ou de outros potencialmente vitais, de modo a promover uma intervenção sustentável (MOURA ET AL, 2006, p. 22).

Cumpre ressaltar que, conforme ainda abordaremos neste artigo, a revitalização dos dois espaços urbanos em foco toca nesses fatores de desvitalização do espaço urbano. $\mathrm{O}$ discurso oficial da gestão municipal de Araguaína, que encontra respaldo no discurso jornalístico, tematiza fatores de desvitalização dos espaços, como até eles se encontravam antes da revitalização. Na seção de análise deste artigo, esses fatores serão detidamente abordados e problematizados.

Consideremos, a seguir, as teorizações de Barreto e Gilson (2013, p. 56), as quais são passíveis de articulação com os referidos apontamentos. É que esses autores, também, salientam o caráter de que o processo de revitalização pressupõe alguns atributos para o espaço a ser revitalizado: (1) reconhecem-se, (2) mantêm-se e (3) introduzem-se valores em uma perspectiva cumulativa. Por isso, o fato de eles ressaltarem, também, que o processo de revitalização é estratégico. Esses atributos nascem, sócio-histórico e ideologicamente, da dialética entre território, atividades e pessoas. Eis os apontamentos dos autores:

A revitalização é um processo de planejamento estratégico, capaz de reconhecer, manter e introduzir valores de forma cumulativa. Dessa maneira, ela intervém a médio e longo prazo, de forma relacional, assumindo e promovendo vínculos entre territórios, atividades e pessoas, e, por conseguinte influencia na melhoria da qualidade do ambiente urbano e nas condições socioeconômicas (MOURA et. al., 2006). Além disso, considera-se que revitalizar é dar vida a um lugar, renovando-o. (BARRETO, GILSON, 2013, 56)

Por Araguaína ser uma cidade média (SODRÉ; RAMIRES, 2017), por se localizar às margens de um corredor viário de relevância nacional, a BR - 153 Belém-Brasília (SANTOS, 2017), observamos a produção discursiva de que esse município é espaço de 
LEITE, J. D; PACÍFICO FILHO, M; MORAES, I. O.

Praça das Nações e parque ecológico Cimba em Araguaína/TO: espaços públicos na Amazônia legal

atração socioeconômica. Tal atratividade resulta em demandas urbano-populacionais por interferências diversas nos espaços públicos. Portanto, centramo-nos nos processos de revitalização pelos quais passaram os espaços públicos supracitados, objetivando nos inserir e contribuir para as discussões acerca das chamadas urbes amazônidas que, segundo Becker (2013), aproximadamente $70 \%$ da população amazônica vivem em cidades, e o tema da urbanização é, significativamente, pouco destacado entre os trabalhos sobre a região.

De acordo com Henri Lefebvre (2006), os processos de urbanização resultam da parametrização pelo capital, materializando sistemas produtivos em que o espaço urbano passa a ser ponto de aplicação do que Álvaro Ferreira (2011) denomina como "economia de consumo". Há valor do solo, das moradias, dos serviços, do consumo, das relações sociais. Nesse sentido, na esteira de Lefebvre (2006), a produção do espaço urbano é marcada por contradições e conflitos. Estabelecendo articulação com o quadro teórico a que nos filiamos, concebemos o espaço urbano sob o viés discursivo. Inscritos em teorizações produzidas por Eni Orlandi (1999), entendemos tais lugares a partir de categorias centrais à Análise de Discurso francesa: política e simbólica. Permitem-nos pensar que o espaço urbano serve para produção de modos de individuação, concebendo o uso em sua materialidade significante (ORLANDI, 1999).

Neste artigo, um dos modos de se dimensionar o processo de revitalização dos espaços em questão é conceber a existência de um discurso urbano sobre Araguaína, particularizando a categoria "organização". Os atributos que mencionamos anteriormente, na esteira de Barreto e Gilson (2013, p. 56), ganham circunscrição pela via de que é preciso "reconhecer, manter e introduzir valores de forma cumulativa" para a produção da organização. Estamos considerando que esses atributos e as discursividades que eles fazem operar, a depender da especificidade do projeto de revitalização, constituem a dimensão política e simbólica da cidade e de seus espaços como materialidades que significam.

A Análise de Discurso francesa, assim como o pensamento de Lefebvre (2006), está alinhada à perspectiva do marxismo histórico. Partindo dessa premissa, a correlação entre dois espaços públicos de Araguaína e determinadas práticas sociais ganham elaboração textual a partir da seguinte estrutura: introdução; seção 1, na qual são expostas as bases teóricas; seção 2, apresentando dados sócio-históricos do município; seção 3, discutindo os espaços públicos e a organização por meio do discurso; e, por fim, nossas considerações. 
LEITE, J. D; PACÍFICO FILHO, M; MORAES, I. O.

Praça das Nações e parque ecológico Cimba em Araguaína/TO: espaços públicos na Amazônia legal

\section{Da “ordem do discurso urbano": incursões teóricas}

Nesta seção, mobilizamos teorizações de Orlandi (1999), referência para a Análise de Discurso francesa, no Brasil; e de Lefebvre (2006), de Ferreira (2011) e de Harvey (2004); teóricos do espaço urbano no âmbito da Geografia. A proposição desse diálogo sustenta-se na convergência de interpretações: trata-se do entendimento de que a lógica capitalista intervém no processo de revitalização dos espaços urbanos. Cada um a seu modo estabelece que há condições sócio-históricas, produzindo, simbolicamente, o espaço do ponto de vista material e imaterial. Assim, lançamos baliza teórica para pensar o modo como o espaço urbano de Araguaína/TO é produzido. Interessa-nos a produção simbólica de dois espaços públicos, notadamente o processo de revitalização pelo qual passaram.

Orlandi (1999), ao conceber a cidade sob uma perspectiva discursiva, postula que o espaço urbano deve ser enfocado em seu poder simbólico por produzir sentidos e o entende a partir de duas categorias centrais para a Análise de Discurso francesa: simbólico e político. É simbólico, porque o espaço urbano funciona, produzindo sentidos com base em sua materialidade. É político, porque os sentidos estão no campo da disputa, pois haverá tantos sentidos quantos forem as pessoas. Não estamos nos referindo apenas à materialidade física (de edificação), mas à significação que as pessoas produzem. A constituição desses sentidos é desigual, pois as condições sócio-históricas e ideológicas acabam singularizando as relações sociais no e pelo espaço urbano diferentemente. Neste momento, não perdemos de vista os atributos que destacamos anteriormente, segundo as considerações de Barreto e Gilson (2013).

Do jogo entre simbólico e político, constitui-se o que Orlandi (1999) denomina “ordem do discurso urbano". É que, na base social, dados os sentidos em disputas, uns se estabilizam e outros se apagam. Para pensar essa ordem, há duas categorias: “ordem” e “organização". A primeira é fruto da produção discursiva, que, de tanto os sentidos sobre o espaço urbano se constituírem, sendo (re)formulados e postos em circulação pelas pessoas, acaba engendrando uma ordem simbólica. A segunda categoria está circunscrita à questão empírica, que se refere à infraestrutura organizacional do espaço urbano. Há um imaginário, tendo por base o modo como a perspectiva discursiva o concebe, que produz a organização, os lugares imaginários para o espaço. No âmbito da Análise de Discurso francesa, o termo “imaginário" refere-se ao registro dos sentidos, da ordem, do efeito da unidade, fazendo-se 
LEITE, J. D; PACÍFICO FILHO, M; MORAES, I. O.

Praça das Nações e parque ecológico Cimba em Araguaína/TO: espaços públicos na Amazônia legal

pensar que as pessoas experimentam o mundo supostamente igual. Consideremos as teorizações da autora:

[...] tal como tenho proposto (E. Orlandi, 1996), deve-se distinguir entre ordem e organização, sendo a ordem do domínio do simbólico (a sistematicidade sujeita a equívoco), na relação com o real, enquanto a organização refere ao empírico e ao imaginário (o arranjo das unidades) (...)nosso objetivo não é pois apenas o de descrever a organização da discursividade urbana, mas sim o de compreender a ordem do discurso urbano, ou seja, entender como o simbólico em sua relação com o político configura sentidos para/na cidade. Em suma, procurando compreender a ordem do discurso urbano, a questão que colocamos é: como a cidade (se) significa? (ORLANDI, 1999, p. 8).

Com base nas disputas de sentidos, entra em jogo o que Orlandi (1999) ressalta como "discurso urbanista”. Há um saber teórico que se historiciza sobre o urbano e que passa a ser (re)atualizado pela incorporação discursiva pelo(s) político(s), pelo(s) gestor(es) e pela população. Daí a divisão desigual dos sentidos sobre o urbano. Orlandi (1999, p. 9) propõe que, a depender dessa incorporação, pode haver "sobreposição do que é conhecimento urbano (sobre a cidade) com a própria materialidade (da cidade)".

Buscando estabelecer relação com autores que se filiam à Geografia, salientamos que essa sobreposição está, inclusive, a serviço da lógica capitalista. Em Ferreira (2011), podemos rememorar que há sistemas produtivos construindo discurso sobre o urbano. Para ele, as cidades no século XXI, por assumirem o "modelo de sucesso internacional", passaram a ser revitalizadas, dados os efeitos das políticas de atração. Assim, cada grupo social experimenta (subjetiva) o espaço desigualmente.

[...] estaremos considerando o espaço como um produto social, mas simultaneamente inter-relacionando-se com a sociedade, ou seja, engendrado pelo modo de produção, sendo produzido para dar sustentação para a estrutura socioeconômica, mas também inter-relacionando-se em todos os níveis, ou seja, com as forças produtivas, organização do trabalho, relações de propriedade, instituições, ideologias etc. (FERREIRA, 2011, p. 33).

Ferreira (2011) mobiliza as teorizações de Lefebvre (2006) justamente para analisar as contradições que o projeto de urbanização das cidades produz, tendo em vista a perspectiva da reestruturação produtiva. Essa reestruturação é concebida como maneira de o capitalismo escapar de suas crises, dado os redimensionamentos espaciais e temporais pelos quais passam as cidades. Na esteira de Lefebvre (2006), a produção do espaço é complexa, pois envolve uma simultaneidade de elementos. O espaço é descoberto, pois há o surgimento 
LEITE, J. D; PACÍFICO FILHO, M; MORAES, I. O.

Praça das Nações e parque ecológico Cimba em Araguaína/TO: espaços públicos na Amazônia legal

de outros espaços em suas dimensões existenciais. O espaço é criação, visto que se produzem, nele e por ele, edificações, paisagens. Consideremos, a seguir, as teorizações de Lefebvre (2006):

[...] o conceito de espaço reúne o mental e o cultural, o social e o histórico. Reconstituindo um processo complexo: descoberta (de espaços novos, desconhecidos, continentes ou o cosmos) - produção (da organização espacial própria a cada sociedade) - criação (de obras: a paisagem, a cidade como a monumentalidade e o décor). (...) (LEFEBVRE, 2006, p.09).

Esse conceito proposto por Lefebvre (2006) tematiza a complexidade que os vários elementos imprimem à produção do espaço. Nossa perspectiva é a de que o espaço urbano de Araguaína é produzido pelo modo como tais elementos ganham circunscrição nessa cidade. Portanto, na próxima seção, mobilizaremos informações para caracterizar Araguaína do ponto de vista sócio-histórico. É importante, na esteira de Lefebvre (2006), não perder de vista a perspectiva do "dispositivo espacial", propondo aproximação conceitual com as teorizações de Orlandi (1999), pensando na organização que opera a produção do espaço urbano.

Harvey (2004) postula a Teoria do Desenvolvimento Geográfico Desigual, vinculando a lógica do capital à dimensão geográfica. Tal autor parte do viés de que a acumulação do capital pode engendrar alterações do espaço e de suas maneiras de espacialidades, produzindo desigualdades. Sendo assim, para Harvey (2004), os desenvolvimentos geográficos são afetados por: (1) acumulação do capital, (2) ação produzida pelo homem na natureza (refere-se à "teia da vida" socioecológica), (3) busca por produzir o tempo de giro do capital (compressão espaço-tempo) e (4) ocorrência de conflitos territoriais em distintas escalas geográficas (municipal, estatal, regional, nacional e internacional).

O pensamento de Harvey (2004) concebe que as práticas sociais são afetadas pela representação do tempo e do espaço. Por assim dizer, estamos interessados na perspectiva de que os dois espaços urbanos enfocados são produzidos por lógicas específicas. Como mostraremos, mais adiante, as práticas sociais características desses espaços são afetadas pelo tempo e pelo espaço. 
LEITE, J. D; PACÍFICO FILHO, M; MORAES, I. O.

Praça das Nações e parque ecológico Cimba em Araguaína/TO: espaços públicos na Amazônia legal

\section{Condições sócio-históricas de Araguaína}

Apresentamos informações sociodemográficas referentes ao município de Araguaína para compreendermos de que modo o espaço urbano é produzido. Nesse sentido, Santos (2017), ao discutir o processo de criação da rodovia BR - 153, menciona que:

[...] um novo processo de urbanização fez com que surgissem várias cidades as margens da rodovia Belém-Brasília, sendo hoje algumas delas as principais do novo estado, tais como: Gurupi, Paraíso, Guaraí, Colinas e Araguaína. Na verdade, a criação da rodovia 153 é resultado de uma política explícita de desenvolvimento e ocupação do Norte (Tocantins e Pará) de forma planejada (SANTOS, 2017, p. 103).

Do ponto de vista discursivo, não podemos nos esquecer de que há uma sobredeterminação sociodemográfica, construindo a "ordem do discurso urbano" sobre Araguaína. Para tanto, vamos recorrer a informações constantes do site do Instituto Brasileiro de Geografia e Estatística (IBGE) e daquelas que foram obtidas, oficialmente, nas secretarias municipais de Araguaína, ou em documentos oficiais, como é o caso do Plano Municipal de Água e Esgoto (PMAE).

O município de Araguaína está localizado na região norte do estado do Tocantins. Consideremos, a seguir, o mapa com a localização geográfica de Araguaína, na sua condição de cidade e de município:

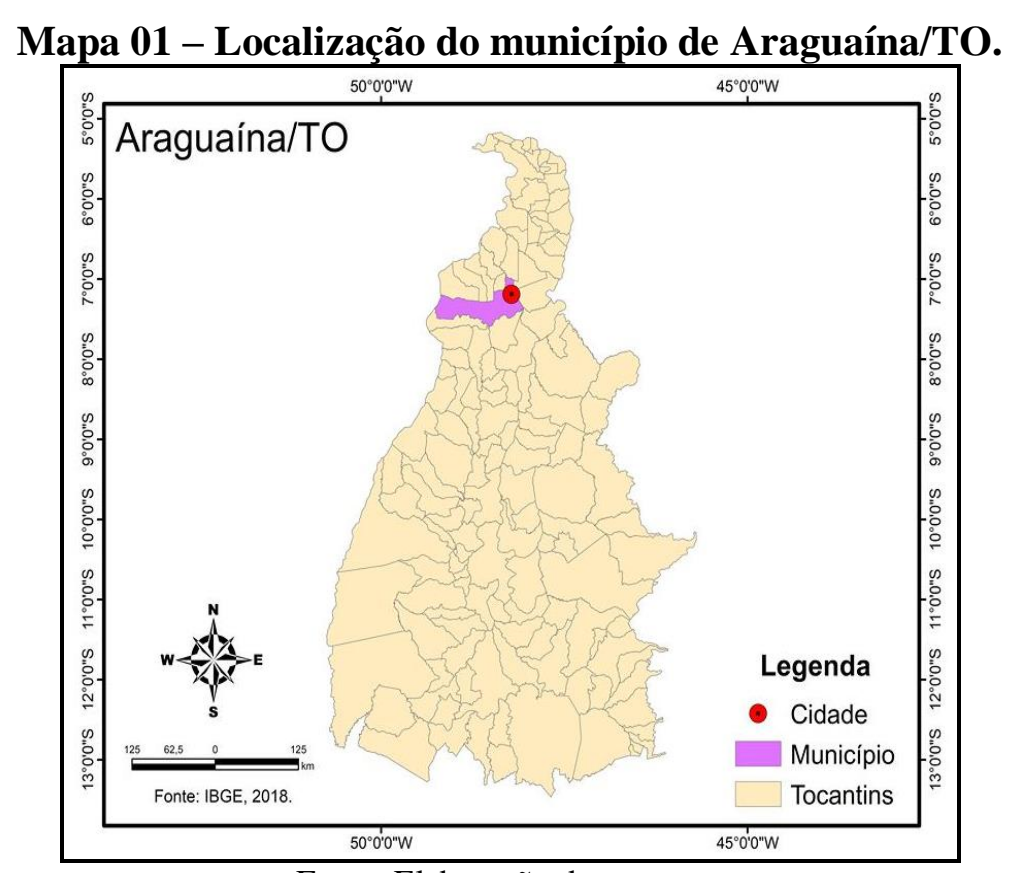

Fonte: Elaboração dos autores.

Revista Cerrados, Montes Claros/MG, v. 18, n. 02, p. 100-122, jul./dez.-2020. 
LEITE, J. D; PACÍFICO FILHO, M; MORAES, I. O.

Praça das Nações e parque ecológico Cimba em Araguaína/TO: espaços públicos na Amazônia legal

No censo demográfico de 2010, totalizou-se a existência de 150.484 pessoas, enquanto a população estimada, para 2019, segundo informações do IBGE, é de 180.470 pessoas. O Plano Municipal de Água e Esgoto (PMAE), de Araguaína (2013), informa sobre a evolução demográfica do município em questão. Ancorados em dados do IBGE, nesse Plano, destaca-se a informação de que, no período de 1970 a 2012, houve um declínio da população rural. Conforme é apresentado no referido Plano, a taxa geométrica de crescimento anual (TGCA) foi negativa, atingindo o valor de $-9,97 \%$, dado o período entre 1991-2000. Nos outros períodos, a taxa foi igual ou menor que $1,00 \%$, o que significa dizer que a população rural manteve estabilidade. Segundo consta do documento, essa taxa negativa deve-se, possivelmente, ao movimento de saída da população rural para a área urbana.

De posse dessas informações sociodemográficas, ainda que de modo sumarizado, é possível destacar que Araguaína é o segundo maior município do estado do Tocantins. Essas informações sobre a evolução populacional são importantes para as discussões que empreendemos, pois, do ponto de vista dos espaços públicos, essa população, certamente, circula ainda mais pela cidade. Não podemos perder de vista a perspectiva que o espaço urbano é produzido, na justa medida em que as pessoas por ele circulam.

A gestão do município, de 2013 até os dias atuais, conforme consta do Portal da Transparência, da Prefeitura Municipal, destinou 3 bilhões de reais para o investimento na construção e/ou na revitalização de espaços públicos. É possível dizer que se busca, nas políticas de atração, implementar infraestrutura, inclusive voltada para a instauração de práticas sociais, como é o caso do lazer. Nessa perspectiva, cabe citarmos a construção do espaço Complexo de Turismo e Negócios da Via lago, na cidade de Araguaína, tendo recebido o seguinte investimento: $\mathrm{R} \$ 22.000 .000$ (vinte e dois milhões de reais). Trata-se de um projeto muito alinhado às dinâmicas de outras cidades em que se estabelece o desenvolvimento geográfico desigual (HARVEY, 2004).

Consideremos, a seguir, a Tabela 1 em que apresentamos os números referentes ao crescimento populacional de Araguaína: 
LEITE, J. D; PACÍFICO FILHO, M; MORAES, I. O.

Praça das Nações e parque ecológico Cimba em Araguaína/TO: espaços públicos na Amazônia legal

Tabela 1 - Crescimento populacional de Araguaína

\begin{tabular}{cc}
\hline Ano & População \\
\hline 1970 & 37.782 \\
\hline 1980 & 72.138 \\
\hline 2000 & 113.143 \\
\hline 2010 & 150.484 \\
\hline 2019 & 180.470 \\
\hline $\begin{array}{c}\text { Elaborado pelos autores. Fonte: IBGE Cidades. Disponível em: } \\
\text { https://cidades.ibge.gov.br/brasil/to/araguaina/panorama }\end{array}$
\end{tabular}

A evolução na taxa de urbanização corresponde, respectivamente, aos seguintes anos e percentuais:

Tabela 2 - Taxa de Urbanização

\begin{tabular}{cc}
\hline Ano & Percentual \\
\hline 1991 & $81,90 \%$ \\
\hline 2000 & $93,58 \%$ \\
\hline 2010 & $94,98 \%$
\end{tabular}

Elaborado pelos autores. Fonte: IBGE Cidades. Disponível em:

<https://cidades.ibge.gov.br/brasil/to/araguaina/panorama>.

Araguaína apresenta duplo movimento em direta relação de causa e de efeito: apresenta crescimento populacional significativo, ao mesmo tempo em que se encontra em posição de referência na hierarquia urbana da região na qual se encontra inserida.

Guardada essa contingência da cidade de Gurupi, esta e Araguaína, no final do século XX, poderiam ser classificadas como cidades médias, tendo em vista as funções exercidas em âmbito regional. Tal condição foi erigida não somente pelas funções desempenhadas por tais centros, mas também pela tenaz estrutura social e econômica dos centros locais e cidades pequenas em seus entornos, o que fortaleceu seus papéis na rede urbana. (SODRÉ e RAMIRES, 2017, p. 177).

Buscando apresentar um panorama das práticas sociais, de modo a relacioná-los aos espaços urbanos, consultamos o site oficial da Prefeitura Municipal pela palavra "cultura". Vejamos, a seguir, um recorte das informações: "atividade cultural”, "período de 
LEITE, J. D; PACÍFICO FILHO, M; MORAES, I. O.

Praça das Nações e parque ecológico Cimba em Araguaína/TO: espaços públicos na Amazônia legal

realização" e "espaço em que ocorreu"; entre os anos de 2013 e 2019, correspondentes aos dois últimos ciclos de gestão municipal, o último deles ainda em vigor. Obtivemos um registro total de 99 ocorrências, e a Tabela 3 demonstra para cada um dos anos uma ocorrência capaz de exemplificar tal dinâmica:

Tabela 3 - Atividades sociais em Araguaína/TO.

\begin{tabular}{|c|c|c|c|}
\hline$N^{o}$ & Atividade & Data & Local \\
\hline 1. & $\begin{array}{c}\text { Oficina de interpretação e } \\
\text { montagem teatral }\end{array}$ & $16 / 09 / 2013$ & $\begin{array}{l}\text { Casa da Cultura, no } \\
\text { Espaço Cultural. }\end{array}$ \\
\hline 2. & $4^{\circ}$ Batizado e Troca de Cordas & $20 / 09 / 2014$ & Praça das Nações \\
\hline 3. & Comemorações da Semana da Água & 23 a $28 / 03 / 2015$ & $\begin{array}{l}\text { Setor Araguaína Sul, na } \\
\text { quadra da Escola } \\
\text { Municipal Dr. Simão Lutz } \\
\text { Kossobutzki. }\end{array}$ \\
\hline 4. & $\begin{array}{l}1^{\circ} \text { Workshop de Natal e Derivados } \\
\text { do pequi }\end{array}$ & $10 / 12 / 2016$ & Praça das Nações \\
\hline 5. & $27^{a}$ Corrida de Rua do Trabalhador & $01 / 05 / 2017$ & Parque Cimba \\
\hline 6. & São João do Cerrado & $\begin{array}{c}21 \mathrm{a} \\
24 / 06 / 2018\end{array}$ & Parque Cimba \\
\hline 7. & Festival São João do Cerrado & 20 a 23/06/2019 & Eco Parque Cimba \\
\hline
\end{tabular}

Fonte: Elaboração dos autores.

Neste ponto, e não perdendo de vista as informações constantes da Tabela 3, podemos dimensionar os apontamentos de Barreto e Gilson (2013), ao tematizar sobre o projeto estratégico da revitalização dos espaços. Essas práticas sociais vivenciadas, nesses dois espaços, demonstram a pertinência e o alcance dos atributos postulados pelos autores, como critério, para que o processo de revitalização seja fomentado e executado. Se correlacionarmos a existência dessas práticas com a taxa de urbanização, que vem em um contínuo de crescimento, segundo consta da Tabela 2, vamos perceber a dimensão do que Sousa et al (2006, p. 22) denomina de "vantagens competitivas e um urbano cada vez mais globalizado". Vejamos, a seguir, mais citação de Sousa et al (2006, p. 58): 
LEITE, J. D; PACÍFICO FILHO, M; MORAES, I. O.

Praça das Nações e parque ecológico Cimba em Araguaína/TO: espaços públicos na Amazônia legal

O objetivo maior da revitalização é atrair para as áreas de intervenção novas famílias, novas atividades econômicas, novos equipamentos coletivos, novas atividades comerciais, mantendo, sempre que possível, as atividades já instaladas, recuperando-as e modernizando-as (MATOS, 2007). Ela é, sobretudo, um instrumento de melhoria das condições de vida da população, através da recuperação de equipamentos públicos e com medidas de dinamização social e econômica.

De posse dessas teorizações, podemos destacar que Araguaína passa por esse discurso de cidade atrativa, tendo em vista que seus espaços são revitalizados, pois se busca atrais pessoas, investimentos, melhorias, dentre outros sistemas produtivos (FERREIRA, 2011). Daí a relevância de entendermos como o discurso da organização ganha a operacionalização por meio de dispositivos de intervenção.

\section{Espaços públicos: discurso da organização}

A compreensão dos espaços delimitados necessita do manuseio de categoria conceitual. Sendo assim, o espaço público converte-se em referência interpretativa. Durante o XVIII (ENANPUR), Rosanelli (2019) expôs estudo de revisão de trabalhos apresentados em quatro versões do evento, com início em 2011. Diz-nos o autor:

[...]o espaço público tem adquirido cada vez mais relevância entre os estudiosos do espaço urbano. Como evidência de tal amplitude, pode-se destacar que a Organização das Nações Unidas (ONU), através do programa que trata das questões dos assentamentos humanos, a UN-HABITAT, tem dado particular atenção ao tema (...) No Brasil, ainda que livros tenham aparecido com menor ênfase, apreende-se que essa discussão tem encontrado terreno fértil em outras esferas de divulgação, como periódicos e eventos científicos (ROSANELLI, 2019, p. 1).

Ressaltamos que tal vitalidade é uma das referências para a proposta de estruturação de quadro referencial atualizado sobre os estudos acerca do tema. O marco temporal supramencionado para o início do levantamento de literatura é também fortemente marcado pelo simbolismo atribuído aos chamados espaços públicos. Diz-nos, novamente, o autor:

[...] optou-se por pesquisar nos anais de encontros que ocorreram a partir de 2011, pois partiu-se de uma hipótese relacionada aos eventos de questionamento da ordem política e econômica instituída em várias partes do mundo, destacadamente a partir de 2010, como por exemplo a "Primavera árabe" 1 (2010), o "Ocupe Wall Street" 2 (2011), e no Brasil, a partir de 2013, pelo "Vem pra rua" 3 (2014) e um dos mais recentes, o "\#elenão" 4 (2018). Portanto, entendia-se que o aumento da ocupação e da visibilidade do espaço público poderia resultar no aumento das pesquisas com foco nessa temática. (ROSANELLI, 2019, p. 2).

Revista Cerrados, Montes Claros/MG, v. 18, n. 02, p. 100-122, jul./dez.-2020. 
LEITE, J. D; PACÍFICO FILHO, M; MORAES, I. O.

Praça das Nações e parque ecológico Cimba em Araguaína/TO: espaços públicos na Amazônia legal

Os eventos mencionados resultam de apresentação de demandas não atendidas das populações envolvidas tanto no que diz respeito à participação popular nas esferas decisórias quanto na percepção de que o Estado deve se reposicionar em atenção ao atendimento dos anseios de setores majoritários das sociedades.

Tal percepção nos leva à exposição do entendimento da concepção de espaço público à qual nos filiamos, que os entende como espaços de tensão, de disputa e de manuseio, de acordo com as perspectivas de mundo dos diversos atores sociais que deles fazem uso. Gomes (2018, p. 117) menciona que:

[...] o funcionamento dos espaços públicos nunca foi pensado como um modelo ideal, de perfeição e obliteração de conflitos. Espaços públicos não são produtos dados e acabados, uma instituição que, uma vez estabelecida, traria a paz da consensualidade e a perfeita igualdade nas sociedades democráticas. Espaços públicos são os lugares em que os problemas aparecem e se transformam em debates, em diálogo e em possibilidade de ajuste e compromissos.

Consideradas as proposições anteriores e referenciadas em Orlandi (1999) para usarmos a diferenciação entre "ordem" e "organização", afirmamos que, dada a realidade de Araguaína mencionada em tópico anterior, há o acirramento do discurso da organização. Há uma discursividade de que o progresso da cidade é indiciado por sua organização; a cidade só é passível de ser subjetivada se seus espaços forem revitalizados. Normalizar significa homogeneizar, inclusive nos moldes de modelos de outras cidades; na esteira de Ferreira (2011), trata-se dos projetos de cidades do século XXI em que a revitalização perpassa projetos de urbanização.

O Mapa 02 apresenta a localização dos espaços em análise. No mapa, à direita, o município de Araguaína, no estado do Tocantins, e, à esquerda, apresentamos, considerando uma imagem de satélite, a localização da Praça das Nações Dom Orione e do Parque Ecológico Cimba. Usamos os nomes populares desses espaços. 
LEITE, J. D; PACÍFICO FILHO, M; MORAES, I. O.

Praça das Nações e parque ecológico Cimba em Araguaína/TO: espaços públicos na Amazônia legal

\section{Mapa 02 - Localização dos espaços urbanos}

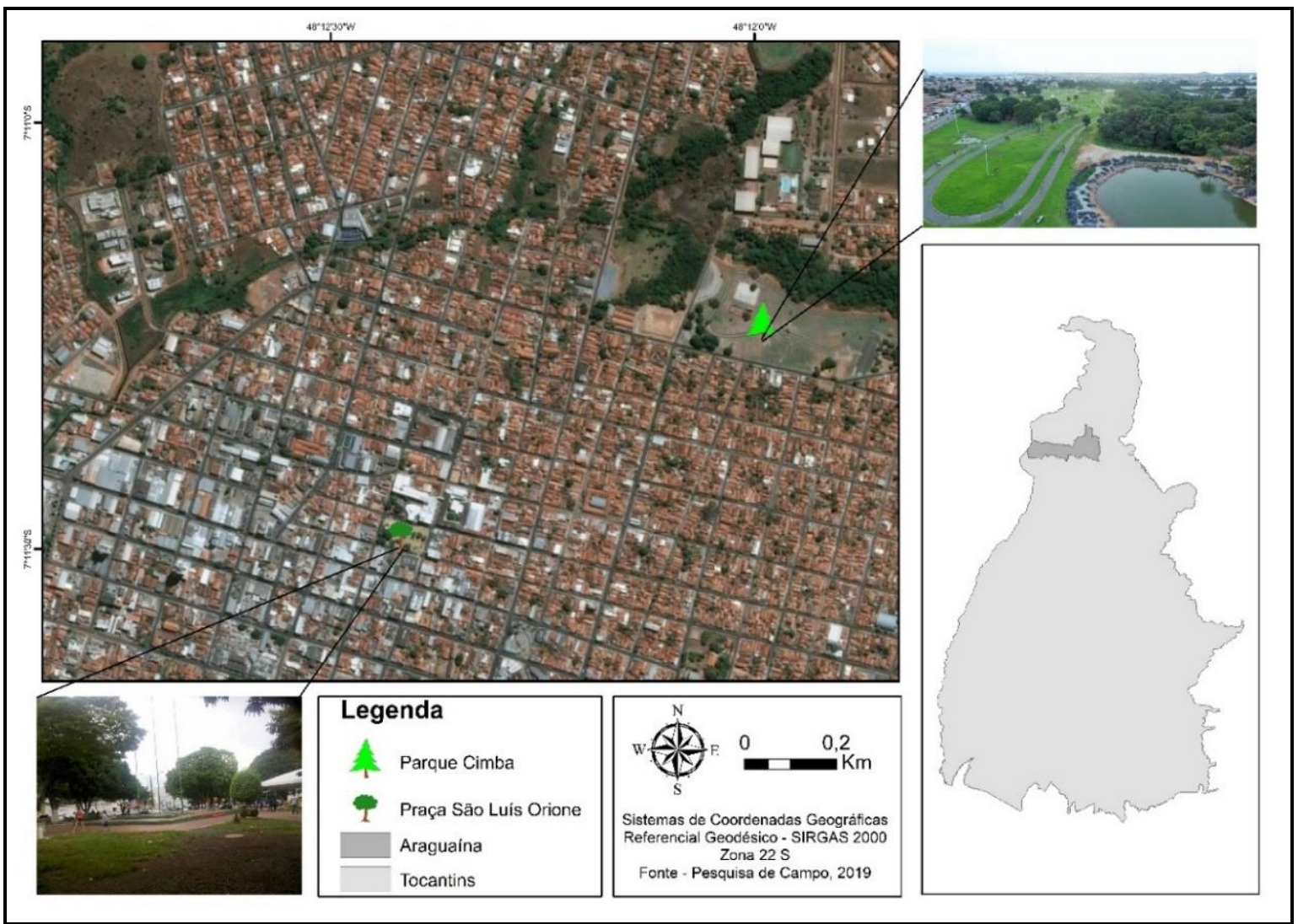

Fonte: Elaboração dos autores.

A Praça das Nações está no setor Central, foi a primeira da cidade; revitalizada e reinaugurada em 2016. Via consultas a portais de notícias de Araguaína, percebemos a construção midiática de que alguns espaços públicos estavam abandonados pela gestão municipal. Citamos a manchete do portal de notícias “O Norte - Quem é daqui acessa!”, do dia 02 de outubro de 2012: "População reclama do descaso com as principais praças da cidade.”. O tom da notícia foi mostrar a insatisfação da população para com as condições observadas. Consideremos, a seguir, um recorte discursivo dessa notícia; cabe ressaltar que o critério de seleção desse recorte foi o momento em que, textualmente, na notícia, a realidade da Praça das Nações foi tematizada:

\section{Recorte discursivo1}

A situação das praças de Araguaína é alvo frequente de reclamações por parte da população (...). A Praça das Bandeiras e a Praça São Luis Orione (mais conhecida como Praça das Nações), ambas no centro da cidade, enfrentam sérios problemas estruturais. Uma equipe do Portal O Norte esteve nas duas principais praças de Araguaína. Lá, além de ouvir a comunidade, constatou, através das lentes de uma câmera fotográfica, inúmeros desafios que se impõem ao poder público municipal. Para a população, não resta dúvidas: já passou do tempo de as praças da cidade 
LEITE, J. D; PACÍFICO FILHO, M; MORAES, I. O.

Praça das Nações e parque ecológico Cimba em Araguaína/TO: espaços públicos na Amazônia legal

\begin{abstract}
passarem por uma reforma efetiva, que privilegie todas as suas características, renovando-lhes a beleza e ampliando o seu alcance. Praca São Luiz Orione. A Praça São Luiz Orione é, de longe, a mais visitada de Araguaína (...). Apesar da movimentação intensa, a Praça das Nações, como também é conhecida, enfrenta o descaso por parte do poder público. Bancos quebrados, lixeiras insuficientes, calçamento rachado, sujeira, canteiros sem manutenção (...). "É uma pena que a praça mais frequentada de Araguaína esteja nestas condições. É vergonhoso que o poder público tenha fechado os olhos para ela. Antigamente, costumava vir mais vezes aqui, mas depois que meu filho se machucou tropeçando num pedaço de banco, passei a repensar as minhas visitas", contou, revoltada, a enfermeira Mônica Carvalho de Assis, de 31 anos. Dona Maria da Paz, de 68 anos, outra assídua frequentadora da praça, concorda. "Araguaína já tem poucos espaços de lazer e os poucos que temos, infelizmente, estão abandonados. Espero que na próxima gestão alguém tome providências. Já basta de descaso!", opinou (...). A população reclama ainda da quantidade de mendigos que fazem da praça sua morada. "Todos os fins de semana, dezenas de mendigos acampam na praça. As vezes passam semanas aqui. Alguns fazem suas necessidades nos canteiros. A sujeira está por toda parte. Além disso, a pintura há muito tempo precisa ser refeita", afirmou o aposentado Marcos Santana, de 71 anos. Durante o dia, o estacionamento da praça, que já tem poucas vagas, serve de espaço para venda de veículos. São dezenas de carros com anúncios de vendas. No ano passado, o Ministério Público Estadual ingressou com uma ação contra a Prefeitura de Araguaína, exigindo a retirada dos automóveis, mas até hoje nada foi feito. "É um absurdo que a praça seja usada para este fim. Pior ainda é que nenhuma providência seja tomada", indagou o servidor público George Mateiros, de 34 anos. [...]

(Notícia de “O Norte - Quem é daqui acessa!”, do dia 02 de outubro de 2012, Grifos da notícia.).
\end{abstract}

Ressaltamos alguns pontos do RD1. O primeiro: a revitalização das praças como demanda de parte da população. De que parte da população se trata? O segundo é a ordem do discurso urbano em operação. É tematizada a necessidade de normalização do espaço público da praça em que tanto a infraestrutura precária incomoda quanto, também, a presença de população em situação de rua. Um dos efeitos da ordem do discurso urbano é a coisificação da condição humana destes, pois eles comprometem a paisagem urbana. Se particularizarmos o seguinte enunciado “A sujeira está por toda parte.”, da enunciação falada atribuída ao aposentado Marcos Santana, vemos o ideário da organização urbana em funcionamento. De que sujeira se trata? Daquela característica do espaço físico? Daquela social em que a população em situação de rua é lida como indício? E quais as medidas públicas passíveis de serem adotadas para a solução da situação?

A praça, como cenário social, não pode ser lugar para a moradia de alguns. $O$ espaço urbano, como lugar em que as relações sociais também acontecem, produz modos de subjetivação diferentes: para alguns, meio de lazer, de bem-estar social; para outros, maneira de se estar na situação de rua. Trata-se de formas sociais concretas, díspares e antagônicas, em que as relações de propriedades são específicas. Revitalizar a praça significa impedir, ainda Revista Cerrados, Montes Claros/MG, v. 18, n. 02, p. 100-122, jul./dez.-2020. 
LEITE, J. D; PACÍFICO FILHO, M; MORAES, I. O.

Praça das Nações e parque ecológico Cimba em Araguaína/TO: espaços públicos na Amazônia legal

mais, o contato entre esses dois perfis de classes que usufruem do espaço urbano. Quando muito podem se estabelecer no campo do mal-estar em que "infraestrutura" e "população em situação de rua" se confundem. Quem está apto, na esteira da ordem do discurso urbano, a ocupar/frequentar a praça? Aqueles que, supostamente, normalizam o espaço? Aqueles que expõem a normalização à falha? A praça é lugar de contradição em que as forças produtivas autorizadas e legitimadas estão à mercê da lógica do capital. Desse modo, é inscrito, na materialidade do urbano, que o quê pode ser básico e essencial para uns, como é o caso de quem "fixa moradia" na praça, para outros pode ser da ordem do lazer, da qualidade de vida, como é o caso de quem "pratica lazer na praça".

Vejamos fotos da referida praça:

Figura 1 - Fotos da Praça das Nações Dom Orione.

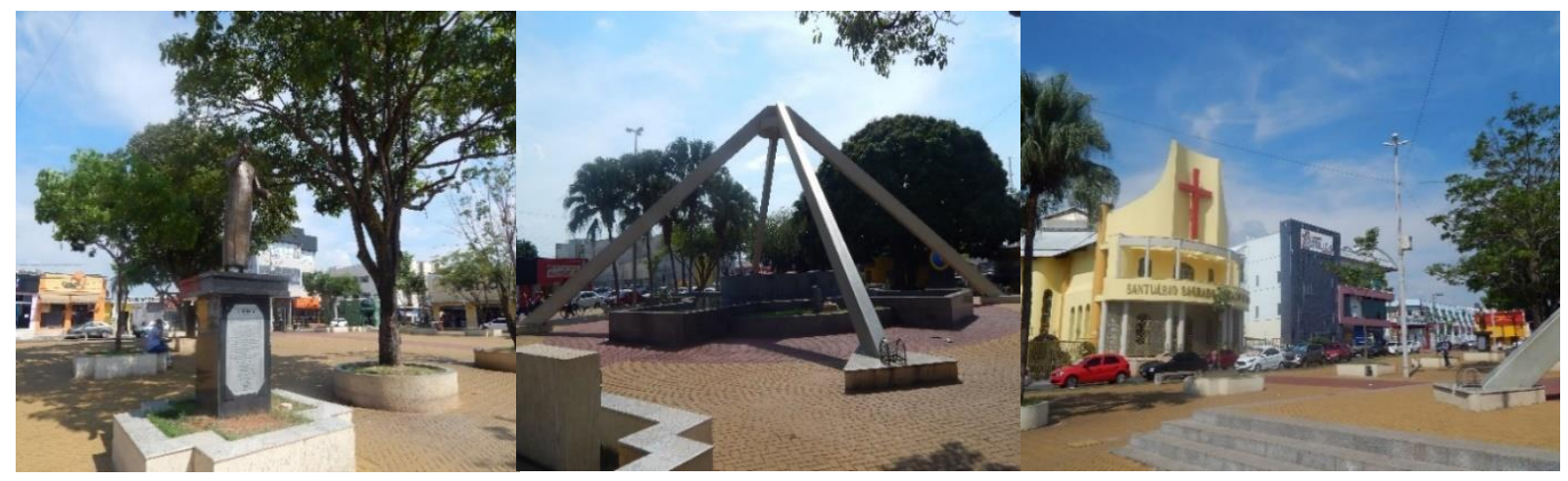

A

B

C

Fonte: Arquivo pessoal.

Na foto "A", aparece o Monumento de Pioneiros, com os nomes das famílias que ajudaram a construir a primeira praça. Trata-se de um monumento datado de 1972, na gestão do prefeito Raimundo Gomes Marinho. Na foto "B", um monumento com uma fonte d'água, o qual se localiza no centro da praça. $\mathrm{Na}$ foto "C", o registro fotográfico apresenta, tangencialmente, a fachada da igreja matriz "Santuário Sagrado Coração de Jesus" e da Faculdade Católica Dom Orione.

O Parque Ecológico Cimba Benedito Vicente está localizado no setor Central, de Araguaína, em um cruzamento urbano importante, ponto de passagem para a população. Nasceu da revitalização do espaço que antes era ocupado pela Companhia Industrial e Mercantil da Bacia Amazônia (CIMBA); a primeira indústria de Araguaína e do então norte 
LEITE, J. D; PACÍFICO FILHO, M; MORAES, I. O.

Praça das Nações e parque ecológico Cimba em Araguaína/TO: espaços públicos na Amazônia legal

goiano, desempenhando atividades de extração, de refinamento e de envasamento de óleo babaçu e industrialização de sabão.

Por meio de consulta ao mesmo Portal jornalístico supracitado, identificamos diferentes entradas de notícias. Selecionamos aquela cuja manchete é "Da indústria ao Parque Cimba: pioneiro conta sobre a transformação do espaço", de 19 de outubro de 2019. O tom da notícia foi tematizar as memórias de Antonio Godoi, com 65 anos, o qual é testemunha da existência da Companhia naquele espaço e, hoje, da existência do Parque Cimba. O teor da notícia foi mostrar o testemunho de pessoas a respeito da transformação do espaço urbano. Consideremos um recorte discursivo da notícia; o critério desse recorte foi seu início e final, quando o paralelo entre Companhia e Parque Cimba é textualizado:

\section{Recorte discursivo 2}

Em 1966, aos doze anos, Antônio Godoi viu pela primeira vez uma indústria. Era a Companhia Industrial e Mercantil da Bacia Amazônica (Cimba), e tanto o nome quanto a imagem ficaram gravados em sua memória. O comerciante, que hoje tem 65 anos, contou como era o complexo industrial que deu lugar à construção do primeiro parque ecológico de Araguaína, o Eco Parque Cimba Benedito Vicente Ferreira. Contada por pessoas que viveram à transformação urbana, esta é a primeira das quatro histórias que serão publicadas em homenagem aos 61 anos de Araguaína (...).

$[\ldots]$

\section{Encerramento da empresa}

Para o comerciante, a crescente demanda do abate bovino na época atraiu a atenção da família para a pecuária e, assim, a Cimba foi caindo de produção e acabou sendo encerrada. "Lá dava emprego para muita gente, que sobrevivia daquilo ali, para o comércio também porque todo mundo que trabalha lá tinha crédito na cidade. Movimentava a cidade".

\section{Construção do parque}

Após o fím da empresa, o local acabou virando um vazio no meio de Araguaína, sendo por muitos anos usado para descarte irregular de lixo. Em 2015, o prefeito Ronaldo Dimas, junto com uma grande equipe de servidores e colaboradores, iniciou a transformação do local para instalação do primeiro parque ecológico urbano da região. Um ano depois, o local já era usado para práticas esportivas e de lazer para todos os araguainenses, sendo usado também para confraternizações, como aniversários, piqueniques e até casamentos. Em 12 de julho de 2019, o parque foi inaugurado oficialmente (...).

(Notícia de “O Norte - Quem é daqui acessa!", do dia 19 de outubro de 2019, às 09h18min. Grifos da notícia.).

Pautados em RD2, ponderarmos os efeitos da ordem do discurso urbano. No caso da revitalização desse espaço, a questão da organização e da normalização é um imperativo. Revitaliza-se para ressignificar. Chamaram-nos a atenção os seguintes trechos desse RD2: “[...] virando um vazio no meio de Araguaína [...]” e "[...] iniciou a transformação do local para instalação do primeiro parque ecológico urbano da região. [...]”. A lógica do capital 
LEITE, J. D; PACÍFICO FILHO, M; MORAES, I. O.

Praça das Nações e parque ecológico Cimba em Araguaína/TO: espaços públicos na Amazônia legal

constrói demanda para a gestão pública municipal: no centro da cidade não são bem-vindos espaços vazios.

A revitalização do espaço, construindo o Parque Ecológico Cimba, tem duplo objetivo: (1) ressignificar o espaço, criando mais uma alternativa de lazer e de qualidade de vida da população; (2) projetar Araguaína, como a cidade que tem o primeiro parque ecológico da região. A ordem do discurso urbano passa a operar com a perspectiva de que Araguaína, para ser uma cidade atrativa, precisa ter seus espaços públicos cuidados, dado o status de cidade polo. Há o ideário de que toda cidade precisa ter um parque ecológico e a tentativa de se assumir um viés de cidade mais "sustentável” e ecológica.

Chama-nos a atenção, em RD2, a marcação de que a revitalização durou um ano, e que, após a inauguração, o espaço já era cenário para diferentes práticas sociais. Ressaltamos que se trata dos "sistemas produtivos", acentuando ou não a "economia de consumo" (FERREIRA, 2011). A ordem do discurso, produzindo o ideário de organização, significa o vazio urbano, como propício para a desordem se instalar: o destino irregular do lixo. Daí a demanda de se revitalizar, sobretudo por estar em um ponto de passagem e de convergência de pessoas.

Como contradição da instalação da desordem no espaço urbano, conforme dá a entrever a notícia em tela, dois questionamentos se (im)põe a nós: (1) haveria falência nos procedimentos de fiscalização do descarte do lixo? (2) população não foi informada acerca da necessidade de destinar o lixo corretamente? Questionamentos, cujas respostas apontam para a complexidade do processo de urbanização. No entanto, observamos que os "sistemas produtivos" produzem o espaço na justa medida em que o capital atribui a ele um valor. Parece ser mais produtivo revitalizar do que fiscalizar e informar a população, pois a especulação territorial ganha condições materiais vantajosas. E os tipos de atividades sociais estão, também, sob a égide da lógica do capital. No caso deste espaço, assim como no outro que abordamos, anteriormente, as práticas sociais passam a ser parâmetro de subjetivação.

Vejamos fotos do Parque Cimba: 
LEITE, J. D; PACÍFICO FILHO, M; MORAES, I. O.

Praça das Nações e parque ecológico Cimba em Araguaína/TO: espaços públicos na Amazônia legal

Figura 2 - Fotos do Parque Cimba

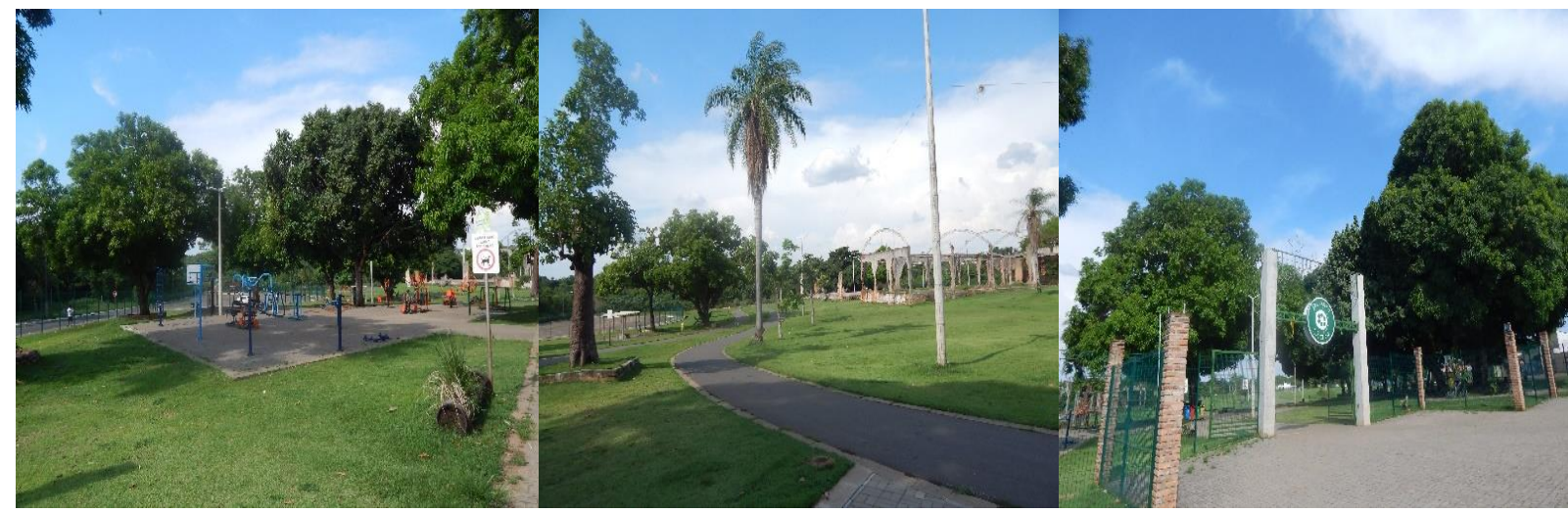

A

B

C

Fonte: Arquivo pessoal.

$\mathrm{Na}$ foto "A", aparece uma quadra esportiva, com aparelhos fixos, a céu aberto; nos quais as pessoas fazem exercícios. Na foto "B”, há visão panorâmica de uma das pistas de caminhada; ao fundo é possível perceber as ruínas que foram conservadas, no processo de revitalização, do espaço que funcionou a Companhia Industrial e Mercantil da Bacia Amazônia (CIMBA). Na foto "C", aparece o portão de entrada principal do parque, localizado próximo a importante cruzamento viário. Constata-se ressignificação dos espaços, sua destinação a lugar de consumo. Ganha-se em valor imobiliário no entorno, educa-se os corpos e indiretamente proporciona-se o desenvolvimento urbano desigual.

\section{CONSIDERAÇÕES FINAIS}

Formulamos diálogo conceitual entre as teorizações de Orlandi (1999), de Ferreira (2011), de Lefebvre (2011) e de Harvey (2004), tendo por base o que esses autores postularam sobre a produção do espaço urbano. Buscamos ainda em Gomes (2018) e em Rosanelli (2019) a delimitação das discussões conceituais em torno dos chamados espaços públicos. Cada um a seu modo, parte de interesses específicos para pensar essa produção. $\mathrm{O}$ diálogo proposto leva em conta o viés marxista que é comum a esses teóricos. O espaço urbano é concebido como uma construção dinâmica, em que a lógica do capital intervém.

Inscritos nesse viés, enfocamos a Praça das Nações e o Parque Cimba como espaços públicos que passaram por processos de revitalização. De nossa perspectiva, entendemos que essa revitalização integra um processo de urbanização da cidade. Por ser uma 
LEITE, J. D; PACÍFICO FILHO, M; MORAES, I. O.

Praça das Nações e parque ecológico Cimba em Araguaína/TO: espaços públicos na Amazônia legal

cidade de porte médio, sobretudo por atrair tantas pessoas de regiões próximas, houve investimentos financeiros no processo de revitalização como um todo. Busca-se, nos moldes da lógica do capitalismo, revitalizar os espaços públicos para torná-los aptos ao uso e à ocupação. Conforme viemos considerando, trata-se de uma revitalização sob o efeito da categoria "organização".

De acordo com Ferreira (2011), dada sua formulação para pensar as cidades do século XXI, essa organização perpassa produzir e/ou revitalizar os espaços urbanos. E, no caso dos espaços em questão, tal revitalização busca expulsar aquilo que, supostamente, pode perturbar a ordem do discurso urbano. Busca-se expulsar população em situação de rua que "fixavam moradia" na praça e os "vazios urbanos", na tentativa de impedir o descarte irregular de lixo.

Na tônica dessa ordem do discurso urbano, as práticas sociais podem figurar como pretexto para se justificar as expulsões. Esses espaços, Praça e Parque, e sua localização geográfica, precisam estar aptos ao uso e a ocupação dos agentes, que, pela lógica do capital, podem colaborar para os sistemas produtivos. Essa ordem deixa entrever que nem "mendigos" nem "lixo" colaboram com a economia de consumo (FERREIRA, 2011). Nesse sentido, o investimento e a sua execução são destinados a espaços urbanos, cujo retorno seja garantido.

É preciso ressaltar que, na produção do espaço urbano, diferentes movimentos podem se delinear. Alguns, notáveis; outros, nem sempre, dada a fugacidade do político e do simbólico em produzir sentidos e sem-sentidos na e pela cidade. Neste artigo, buscamos mostrar que essa produção é desigual e contraditória.

\section{AGRADECIMENTOS}

Agradecem a CAPES pelo apoio institucional aos PPGs dos quais são parte.

\section{REFERÊNCIAS}

BARRETTO, Margarita; GISLON, Milanez. O flâneur revisitado: processos de revitalização urbana e caminhabilidade. Revista Hospitalidade, São Paulo, v. X, n. 1, p. 54 - 77, jun. 2013.

BATISTA, Maurício Nogueira. Notas sobre o problema urbano. Instituto de Pesquisa Econômico Social - Aplicada (IPEA) setor de Documentação, 1969. Disponível em: http://repositorio.ipea.gov.br/handle/11058/7883. Consulta em 11/06/2020. 
LEITE, J. D; PACÍFICO FILHO, M; MORAES, I. O.

Praça das Nações e parque ecológico Cimba em Araguaína/TO: espaços públicos na Amazônia legal

BECKER, Bertha K. Novas territorialidades na Amazônia: desafio às políticas públicas. In:

Boletim Museu Paraense Emílio Goeldi: Ciências Humanas, vol. 5. P. 17 - 23, 2010.

BECKER, Bertha K. A urbe amazônida: a floresta e a cidade. Rio de Janeiro: Garamond, 2013.

CABRAL, Laíse do Nascimento; CÂNDIDO, Gesinaldo Ataíde. Urbanização, vulnerabilidade, resiliência: relações conceituais e compreensões de causa e efeito. urbe.

Revista Brasileira de Gestão Urbana, vol. 11.p. 1 - 13, 2019.

CARLOS, Ana Fani. A cidade. São Paulo: Contexto, 1992.

CARLOS, Ana Fani. A produção do espaço urbano: agentes e processos, escalas e desafios. São Paulo: Contexto, 2011.

FERREIRA, Álvaro. A cidade no século XXI - Segregação e banalização do espaço. Rio de Janeiro: Consequência, 2011.

GOMES, Paulo Cesar da Costa. Espaço público, espaços públicos. GEOgraphia, Niterói, v. 20, n. 44, p. 115-119, 2018.

GOMES JUNIOR, Evaldo; NASCIMENTO, Humberto Miranda. A centralidade do município de Araguaína - TO na Amazônia Oriental. In: Anais do XIII Seminário

Internacional RII e VI Taller de Editores RIER. Salvador, 01 a 04 de setembro de 2014, p. 1 a 15.

HARVEY, David. Espaços de esperança. São Paulo: Loyola, 2004.

LIMONAD, Ester. Reflexões sobre o espaço, o urbano e a urbanização. GEOgraphia, Niterói, v. 1, n. 1, p. 71-91, 1999.

LEFEBVRE, Henri. A produção do espaço. Trad. Doralice Barros Pereira e Sérgio Martins (do original: La production de l'espace. 4e éd. Paris: Éditions Anthropos, 2000). Primeira versão: início - fev.2006.

MARICATO, Ermínia. Brasil, cidades: alternativas para a crise urbana. Petrópolis, RJ: Vozes, 2001.

MARICATO, Ermínia. Para entender a crise urbana. São Paulo: Expressão Popular, 2015.

MOURA, Dulce et.al. A revitalização urbana - contributos para a definição de um conceito operativo. In: Cidades - Comunidades e Territórios. Lisboa, n.0 12/13, 2006, pp. 13- 32.

ORLANDI, Eni. N/O Limiar da cidade. Rua, Campinas, v. 5, Número especial, p. 7-19, 1999.

População reclama do descaso com as principais praças da cidade. In: O Norte - Quem é daqui acessa! Disponível em: http://www.portalonorte.com.br/araguaina/populacao-reclamado-descaso-com-as-principais-pracas-da-cidade/50988/. Acessado em 30 de outubro de 2019. 
LEITE, J. D; PACÍFICO FILHO, M; MORAES, I. O.

Praça das Nações e parque ecológico Cimba em Araguaína/TO: espaços públicos na Amazônia legal

Da indústria ao Parque Cimba: pioneiro conta sobre a transformação do espaço. In: O Norte Quem é daqui acessa! Disponível em: https://www.portalonorte.com.br/noticias/pioneiroconta-sobre-a-transformacao-da-industria-ao-1o-parque/92991/. Acessado em 30 de outubro de 2019.

ROLNIK, Raquel. O que é cidade. São Paulo: Brasiliense, 1988.

ROSANELI, Alessandro Filla et. al. O conceito de espaço público: sucinta revisão de literatura em artigos dos ENANPUR. In: Anais XVIII ENANPUR, 2019.

SANTOS, Roberto Souza. A construção da rodovia BR - 153 na fronteira e urbanização da cidade de Araguaína, Tocantins. Novos Cadernos NAEA, v. 20, n. 3, p. 97-114; set-dez 2017.

SODRÉ, Reges; RAMIRES, Júlio Cesar de Lima. Contribuições ao estudo de cidades médias: Araguaína, Gurupi e Palmas, no Tocantins. Novos Cadernos NAEA, v. 20, n. 1, p. 169-188, jan-abr 2017.

\section{Autores}

João de Deus Leite - É Graduado no Curso de Letras/Português, pela Universidade Estadual de Montes Claros (UNIMONTES); é Mestre e Doutor em Estudos Linguísticos, pela Universidade Federal de Uberlândia (UFU). É Professor Adjunto na Universidade Federal do Tocantins (UFT).

Miguel Pacífico Filho - É Graduado no curso de História pela Universidade Federal de Ouro Preto (UFOP); Mestre e Doutor em História, pela Universidade Estadual Paulista Júlio de Mesquita Filho (UNESP). Professor Associado II na Universidade Federal do Tocantins (UFT).

Izabel Oliveira de Moraes - É Graduada em História, pela Universidade Estadual de Montes Claros (UNIMONTES). Possui Graduação em Letras (Língua Portuguesa e Literaturas), pela Universidade Federal do Tocantins (UFT). Possui Pós-Graduação em Arte e Educação pela Universidade Federal do Tocantins (UFT).

Artigo recebido em: 18 de julho de 2020.

Artigo aceito em: 14 de agosto de 2020 .

Artigo publicado em: 19 de agosto de 2020 . 